\title{
Mangler der ikke en romanserie om en dansk søkrigshelt?
}

af dr.phil. Jens Chr. V. Johansen

Det Kongelige Biblioteks sommerudstilling 2010 er en scrudstilling $i$ anledning af den danske flades 500 års jubilaum, men begranset til det 18. årbundrede og en sarlig synsvinkel belyst ud fra soofficeren Peter Christian Schionnings (1732-1813) enorme arkiv og samlinger, der borer til de absolut storste privatarkiver fra Oplysningstiden og alene rummer 73 poster $i$ Håndskriftsbasen, Håndskriftsafdelingen nye falleskatalog (se også > bttp:/ / wnwn.orlogsmuseet.dk/samling.htm). Samlingerne blev afleveret til Universitetsbiblioteket umiddelbart efter Schionnings dod i 1813. Udstillingen Flåden i krig og fred. Den Kongelige Søetat i 1700-tallet, der er resultatet af et samarbejde med Statens Forsvarshistoriske Museum (Tojbusmuseet og Orlogsmuseet), redigeres af museumsinspektor Jakob Seerup, Tojbusmuseet, og forskningsbibliotekar Jesper Düring Jorgensen, Det Kongelige Bibliotek.

Udstillingen kommer til at rumme et sarligt

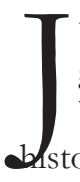

uel, Tordenskjold og Willemoes er givetvis de navne, der lyser klarest blandt stjernerne i den danske flådes Llstorie. Alligevel er det kun Tordenskjold, der har haft hovedrollen i romaner og film. Ganske anderledes forholder det sig, hvis vi vender os mod den engelske krigsflåde. Mange kender navnene Horatio Hornblower, Jack Aubrey og Ni- afsnit om historiske sokrigsromaner, en genre som ikeke har den store tradition i Danmark, men er meget popular $i$ England, der gennem oversattelser også har et stort publikum $i$ Danmark. Men i 2009 udsendte historikeren, ph.d. Dan H. Andersen, der bl.a. i 2004 skrev den forste danske faghistoriske biografi om Tordenskjold i 250 ar (Mandsmod og kongegunst, der i 2010 er udkommet $i$ en revideret udgave), et skonlitterart forsog i genren, Tordenskjolds Skygge, som bind $14 i$ den skonlitterare Danmarkshistorie Slagten, som Det Historiske Hus Aps i Odense har udviklet, og som udgives på forlaget Lindhardt og Ringhof.

I anledning af udstillingen har Det Kongelige Bibliotele bedt historikeren, dr. phil. Jens Christian $V$. Johansen, der ogsà er en meget kyndig kender af historiske romaner, om at skrive om den engelske historiske sokrigsroman.

Erland Kolding Nielsen

cholas Ramage, men der er flere endnu: Richard Bolitho, Nathaniel Drinkwater, Thomas Kydd, Alan Lewrie og Nathan Peake. Mens de danske flådeheltes historie spreder sig over en periode på ca. 150 år (fra Svenskekrigene i det 17. århundredes sidste fjerdedel til Englandskrigene i begyndelsen af det 19 . århundrede), er det påfaldende, at de en- 


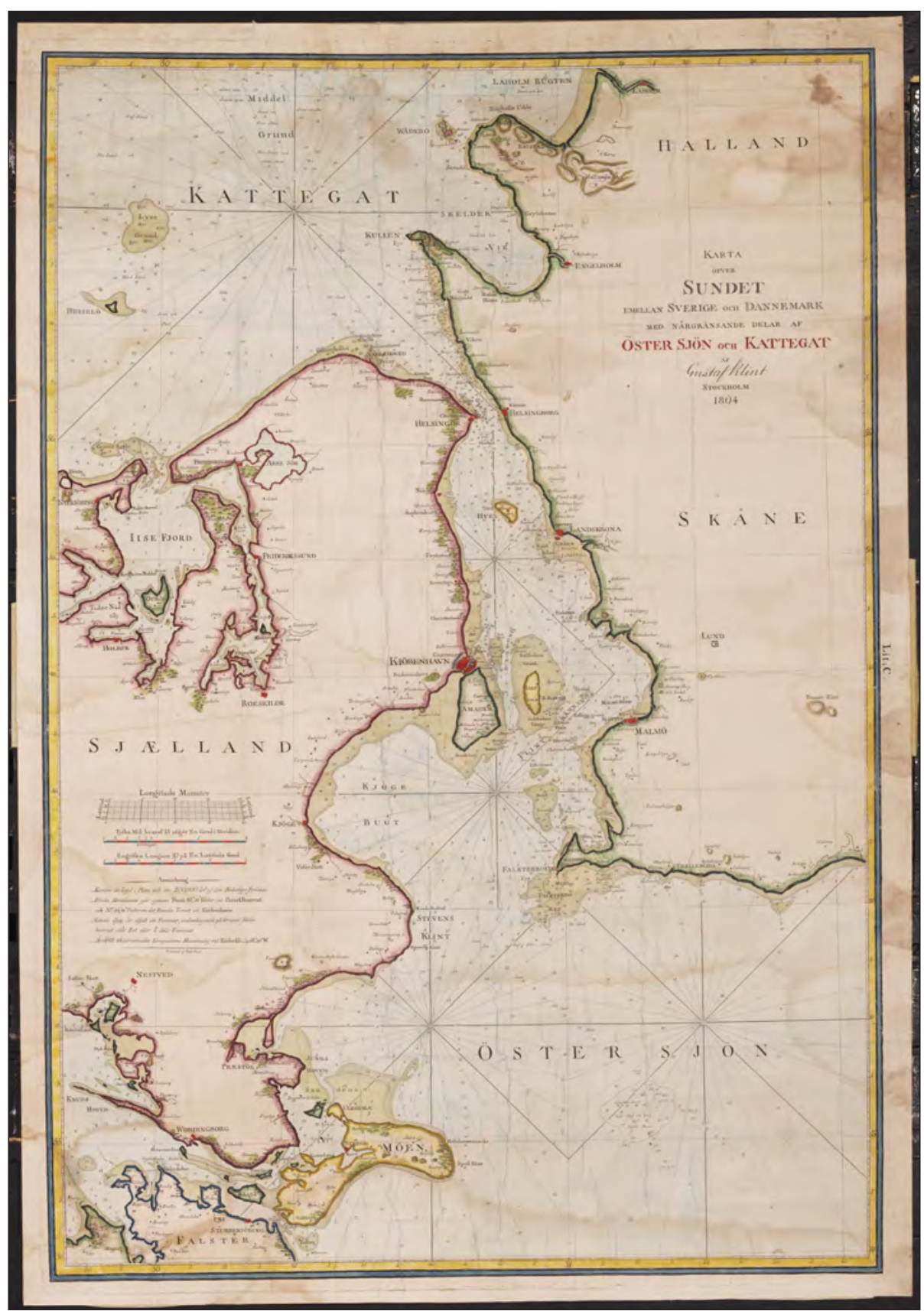

Karta öfver sundet emellan Sverige och Dannemark med närgränsande delar af Östersjön och Kattegat, Stockholm 1804, som Hornblower kunne have benyttet (Det Kongelige Bibliotek). 
gelske fiktive søhelte alle optræder under Napoleonskrigene.

Horatio Hornblower er nok mest kendt. Det skyldes, at han foruden i bøgerne også har optrådt på film og $\mathrm{i}$ en tv-serie. Forfatteren er C.S. Forester, der første gang lader sin hovedperson optræde som en søsyg kadet på en hemmelig mission til Centralamerika. I de efterfølgende romaner følger læserne Hornblowers karriere gennem Napoleonskrigene, indtil han forfremmes til admiral og adles som baron Hornblower i The Most Honorable Order of the Bath, der var blevet grundlagt af kong George I i 1725. Forester skrev sine romaner på den måde, at Hornblower aldrig rigtigt var indblandet $\mathrm{i}$ de store søslag under Napoleonskrigene, fordi han var blevet sendt på en anden samtidig mission.

Hornblower var født i Kent tidligt i 1780'erne som søn af en læge, der hverken havde økonomiske midler eller indflydelsesrige venner. Da Forester imidlertid $i$ bind 6 besluttede sig til at skrive om Hornblowers tidlige liv, blev han fødselsdato også ændret, således at han blev født på den amerikanske uafhængighedsdag. Med en klassisk uddannelse som baggrund kan han som 17-årig optages i den engelske flåde som kadet med gode kundskaber i græsk og latin; hans naturlig anlæg for matematik giver ham gode evner som navigatør. Hans karriere er fyldt med ned- såvel som opgang; allerede som ung kadet er han i stand til sammen med mandskabet at afvise fem fjendtlige skibe, men da han så får kommando over sluppen Le Rêve, ramler han i tåge ind i en spansk flåde, hvilket medfører et ophold i fængslet i Ferrol. Men intet er så skidt, at det ikke er godt for noget, da fængselsopholdet gør Hornblower i stand til at tale flydende spansk, hvilket kommer ham til gode i senere romaner.

For danskere er den mest interessante roman givetvis The Commodore (på dansk Hornblower i Østersoen), i hvilken Hornblower udnævnes til kommandør og sendes på en mission til Østersøen. Romanen foregår i 1812, og på Peterhof forhindrer han et attentat på den russiske zar. Denne handling er selvsagt med til at overbevise zaren om, at han skal kæmpe imod Napoleons invasion af Rusland. I et efterfølgende bind i serien, Hornblower in the West Indies, kommer Hornblower atter på tværs af Napoleon, da han forhindrer et forsøg fra den kejserlige gardes veteraner i at befri ham fra fangenskabet på Skt. Helena. Senere i The Commodore deltager Hornblower ved forsvaret af Riga, hvor han møder den berømte militærteoretiker Carl von Clausewitz, der var i russiske tjeneste. Skønt langt størstedelen af Hornblower $i$ Østersoen foregår i den østlige del af Østersøen, følger læserne alligevel Hornblowers sejlads gennem Øresund, hvor strækningen fra Kullen til Saltholm beskrives indgående.

Der er intet i vejen med Foresters viden om forholdene ved denne sejlads; ved Kullen bemærker Hornblower, at det vil vare otte timer, før de "var vel forbi Saltholm og nogenlunde uden for fare". ${ }^{1}$ Men det er ikke den store respekt, der lyder om besætningen og skildvagterne på Kronborg (og det er selvfølgelig også kun få år efter, at 


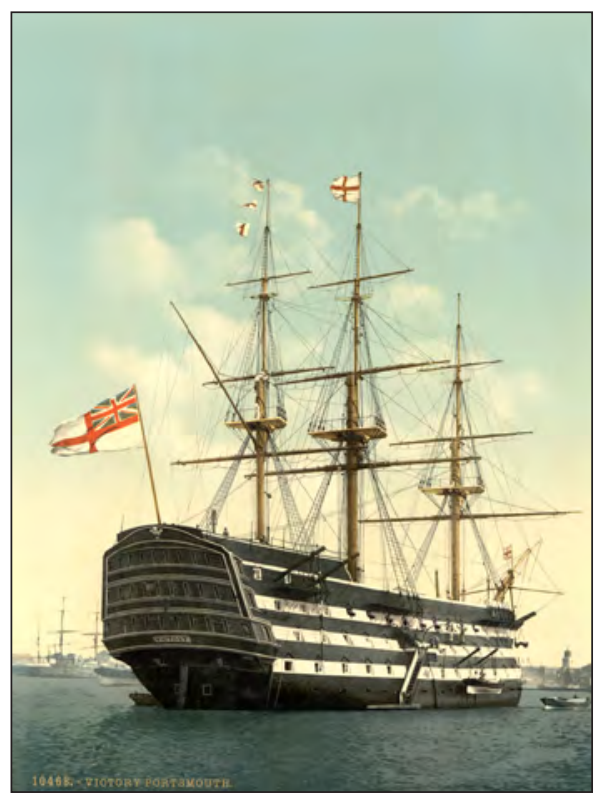

Et linieskib havde to eller flere dak, bvorpà der var anbragt 50 til 130 kanoner. Linieskibet HMS Victory, bygget 1759-1765, og som bl.a. blev fort af viceadmiral Horatio Nelson i slaget ved Trafalgar, var udstyret med 104 kanoner.

den engelske flåde havde bortført den danske). Der affyres kun fire kanonskud mod de engelske skibe, og så er skibene nået i sikkerhed på den side af Hven, der vender over mod Sverige. For der lød ingen skud fra svenske side, så Hornblower kan konkludere, at Bernadotte opretholdt sin neutralitet og ikke havde besluttet sig for at gå ind i krigen på sit gamle fædrelands side. Faren ville opstå, når de engelske skibe nåede frem til Saltholm og Amager, da "begge øerne var på danske hænder". Hornblowers skibe blev da også beskudt fra de to øer, men ikke så alvorligt, at de ikke kunne komme væk fra beskydningen og ind i Østersøen. Der var nu ingen batterier på Saltholm, men på Amager var der Stric- kers batteri lige syd for Lynetten, og så var der et lille batteri ved Kastrup (som langt senere blev til Kastrupfortet). ${ }^{2}$

\section{f de andre forfattere er Dudley Pope med sine 18 romaner om 1 Nicholas Ramage den, der ville} have haft de bedste muligheder for at skrive om forhold tæt på Danmark, eftersom han i 1978 i The Great Gamble: Nelson at Copenhagen skrev videnskabeligt om slaget på Reden, men året 1801 er udeladt i serien. Han kunne egentlig også have skrevet om forholdene i 1807, da den danske flåde blev beslaglagt af den engelske, men attende og sidste bind i Ramage-serien stopper med begivenheder i 1806.

I Richard Woodmans serie

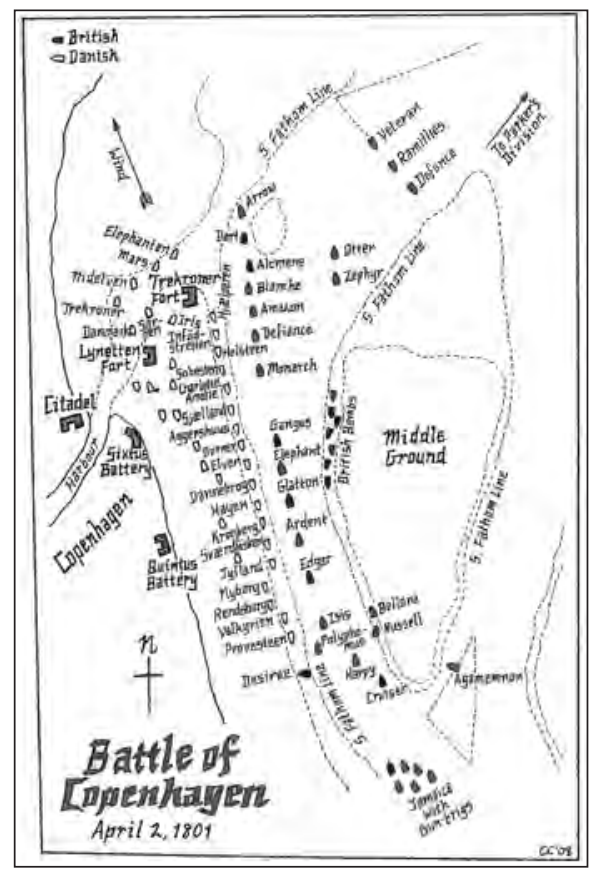

Slaget på Reden 1801. Fra Dewey Lambdin The Baltic Gambit, 2009. 


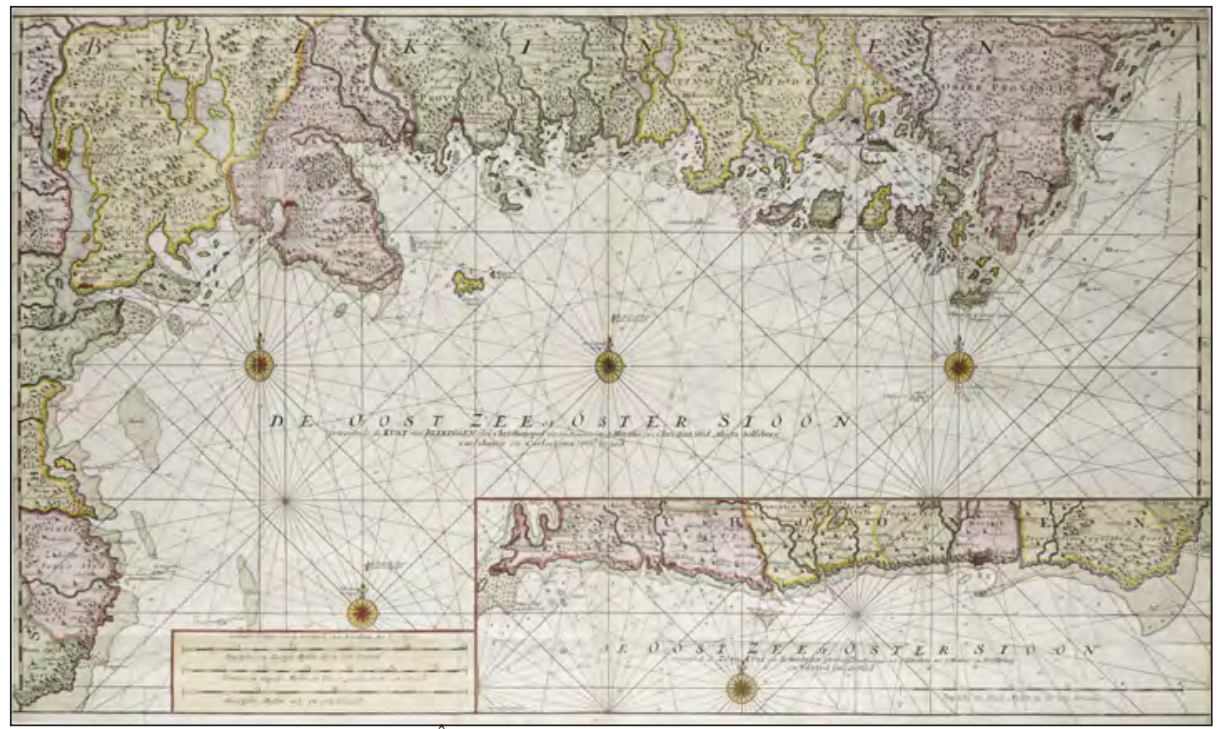

Gerard van Keulens De Oost Zee af Ôster Siöön, Amsterdam 1730 (Det Kongelige Bibliotek).

om Nathaniel Drinkwater begiver engelske skibe i romanen Baltic Mission i 1807 sig også ind i Østersøen med den opgave at hindre en fransk-russisk alliance. Ud for Kronborg standser det danske linjeskib Prinsesse Sophia Frederica (bygget 1774) det engelske skib og advarer det mod at opbringe danske skibe. Woodmans kendskab til danske forhold viser sig, da hans skib Antigone ud for Bornholm tager Birthe af Grenå som prise og kaptajn Nielsen udbryder " $\AA$ for helvede" med bolle-å - og uden "h".

Woodmans The Bomb Vessel har dog mere handling med direkte relation til Danmark, eftersom Drinkwater i denne roman deltager og udmærker sig $\mathrm{i}$ slaget på Reden i 1801.

Dewey Lambdins The Baltic Gambit kommer også direkte ind i dette slag. Hovedpersonen er Alan Lewrie, som efter en mission til Skt. Petersborg, hvor han skal aflevere nogle russere, som er blevet transporteret fra England, på tilbagevejen støder til Nelsons flåde ved København. Dewey Lambdin har et solidt kendskab til den danske flådes operationer i Middelhavet i slutningen af 1700-tallet, efter at korsarstaten Tripoli havde erklæret Danmark krig, og til det væbnede neutralitetsforbund. Det sidste væbnede neutralitetsforbund, Danmark deltog i, blev indgået i 1800 mellem Rusland, Danmark-Norge og Sverige og siden tiltrådt af Preussen. Op gennem 1700-tallet drejede uoverensstemmelsen mellem de neutrale og de krigsførende magter sig om neutrale handelsskibes ret til fri sejlads over for krigsførende staters ret til at visitere, opbringe og evt. konfiskere neutrale skibe og deres ladninger. Også Struensees meriter omtales (ret overbærende). 
(og Lambdin), når han kommer nærmere ind på de geografiske forhold. Om det er fordi, han opfatter Jylland som en $\varnothing$, at han kan se Thisted på sejladsen mod Skagen for at stævne mod Østersøen, vides ikke. Ligesom ved sin omtale af Struensee nærer Lambdin ikke de højeste tanker om den danske besætning på Kronborg, da officererne på det engelske skib diskuterer, hvorledes man skal passere fæstningen. Eftersom der i over 80 år kun er blevet saluteret fra Kronborg, finder Alan Lewrie, at man skal gå ned gennem Øresund lige midt imellem Helsingborg og Kronborg, da danskerne ikke kunne ramme "Westminster Cathedral if it was anchored in mid-stream between 'em'.

Til gengæld er hans beskrivelse af slaget på Reden solidt krydret med et meget præcist kort over skibsformationerne.

$\mathrm{H}$ vad er det, der gør disse serier med historisk indhold så populære? Der er givetvis flere grunde hertil. ${ }^{3}$ Men for søkrigsromanerne gælder det nok især, at flere af romanerne er skrevet af forfattere med et indgående kendskab til forholdene i flåden. Det gælder f.eks. Alexander Kent, Dewey Lambdin og Julian Stockwin, der alle på et eller andet tidspunkt har været i flåden. Selvom forfatterne til middelalderkrimierne (se Jens Chr. Johansen: 'Broder Cadfael og Søster Fidelma. Den historiske krimiserie. Oplysning og underholdning, Bogens Verden 2003, 3) er historikere eller litterater, kan de ikke have sammen indgående kendskab til forholdene, som når en fuldbefaren

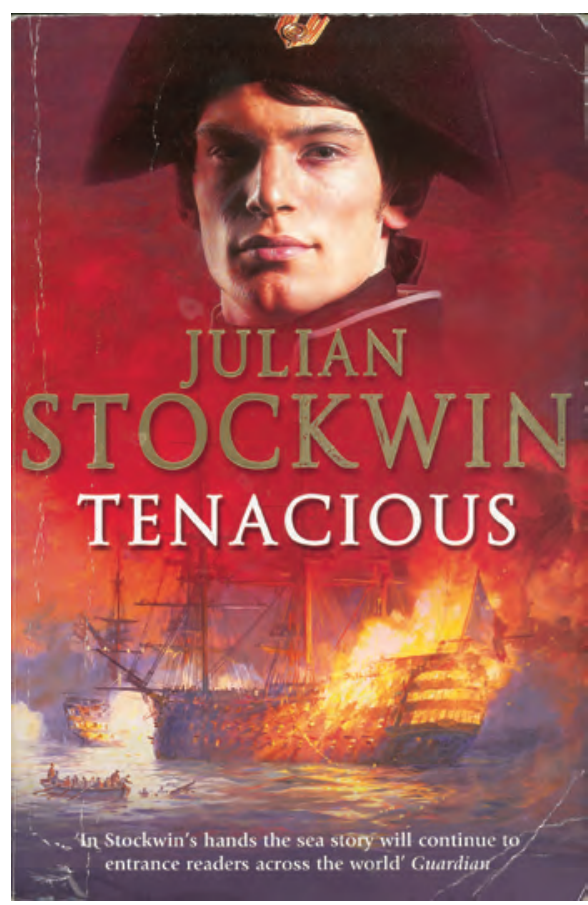

Forside fra en Thomas Kydd-roman.

sømand skriver om de skibe, de ganske vist ikke har sejlet, men som alligevel fungerer på nogenlunde tilsvarende vis som moderne skibe.

Som det er sket for nogle af middelalderdetektiverne (f.eks. Broder Cadfael og Soster Fidelma) er der blevet oprettet selskaber (det drejer sig bl.a. om et C.S. Forester Society og et Thomas Kydd Society), hvorigennem man kan diskutere sin romanhelt med andre ligesindede, købe plakater af de udgivne bøgers forsider eller vandre i deres fodspor (for søkrigsheltenes vedkommende må det vel blive: sejle i deres kølvand).

Disse selskaber synes inspireret af de store fodboldklubbers merchandise-salg, som det bl.a. ses i Real Madrid eller Manchester United. Det er givetvis 
denne mulighed for at komme nær på de fiktive helte, der har været med til at forøge deres popularitet. Læsernes kan identificere sig med deres helte, når man kan stå i haven i klostret i Shrewsbury, hvor Broder Cadfael plukkede sine helbredende urter eller sejle ud fra samme havn, som Thomas Kydd stævnede ud fra.

Populariteten skyldes også, at læserne af en serie lærer hovedpersonerne bedre at kende, og at vi via gentagelserne, som en litteraturforsker har udtrykt det, oplever den "ultimative tryghed".

Hvis man ikke har havvand $\mathrm{i}$ blodet, er romanernes største handicap det meget begrænsede rum, hvori de udspilles. Et skibsdæk kan ikke beskrives på mange forskellige måder uden fare for stereotype gentagelser, og de fleste forfattere lader da også deres hovedpersoner søge land for at få gang i en lidt mere udviklet handling. Patrick O’Brian er nok den, der løser dette dilemma mest elegant, når han lader kaptajn Jack Aubrey og skibslægen Stephen Maturin spillede cello- og violinduoer i kaptajnens kahyt (tilsyneladende til mandskabets uudtalte mishag).

Nogle forfattere er uhyre meget bedre end andre til at beskrive den ufattelige gru, besætningerne må have oplevet, når de fjendtlige kanonkugler splintrede masterne og slog ind på kanondækket. I filmen Master and Commander ser vi skibslægernes forsøg på at begrænse de skader, mandskabet er blevet tilføjet.

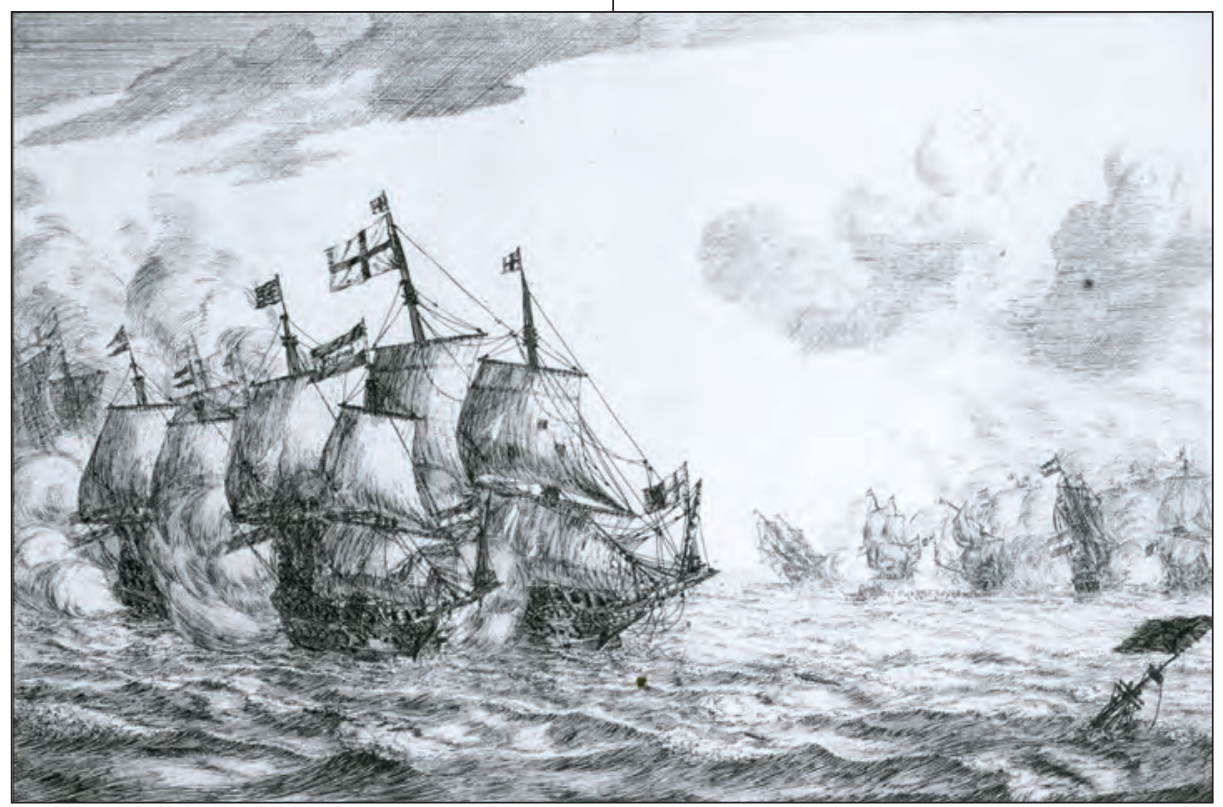

En dansk sobelt, Niels Juel, deltog på hollandsk side i fire af slagene under den engelsk-hollandske krig 1652-54. På denne tegning af Reinier Nooms ses de hollandske skibe i baggrunden. Fra Niels M. Probst Niels Juel. Vor største flådefører, 2005.

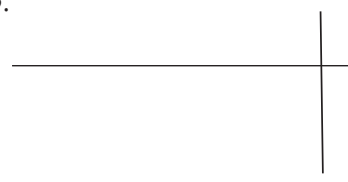


$\mathrm{H}$ vorfor er der så ingen romanserie om en dansk søkrigshelt? Oplagt er det at pege på, at der ingen tradition findes i Danmark for skumsprøjtsromaner (når man ser bort fra Peder Most), eller i det hele taget for serier med et historisk indhold. Skønt det skal siges, at der i det sidste tiår er udkommet to middelalderkrimiserier: Birgitte Jørkovs om købmandsenken Elne Jeps fra Helsingør og Martin Jensens om Assens-byfogeden Eske Litle. Nok væsentligere end den manglende tradition er det forhold, at landet i mange år har været den tabende part $\mathrm{i}$ de krige, vi har deltaget i. Og hvem har lyst til at skulle gentage det $\mathrm{i}$ roman efter roman? Tordenskjold kan benyttes, for når alt kom til alt, endte Store Nordiske Krig uden egentlig sejrherre - og han snød konstant arvefjenden.

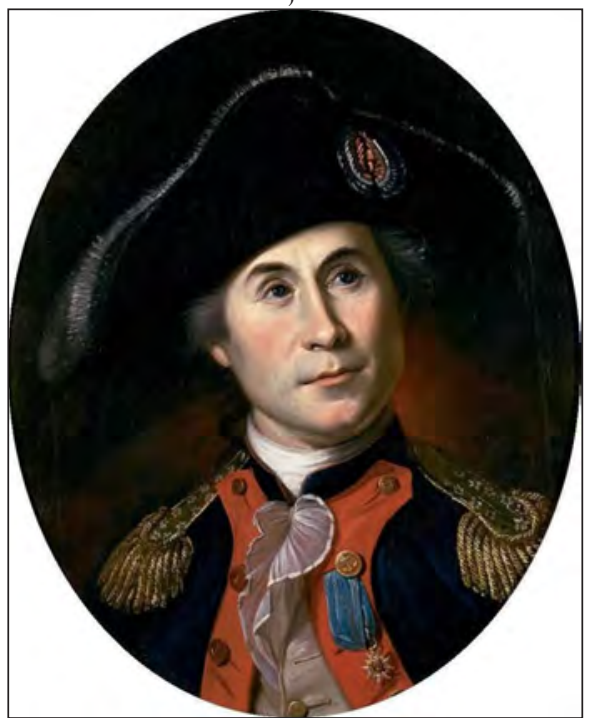

John Paul Jones (1747-1792) var den forste amerikanske sobelt. Han er kendt for sin indsats $i$ den amerikanske uafhangighedskrig. Maleri af Charles Willson Peale, 1781.

\section{Filmografi:}

'Midshipman Easy' (1935) Instruktør: Carol Reed

'Captain Horatio Hornblower R.N.' (1951) Instruktør. Raoul Walsh

'John Paul Jones' (1959) Instruktør: John Farrow

'Billy Budd' (1962) Instruktør: Peter Ustinov

'H.M.S. Defiant' (1962) Instruktør: Lewis Gilbert

'Master and Commander: The Far Side of the World' (2003) Instruktør: Peter Weir

'Tordenskjold gaar i land' (1942) Instruktør: George Schneevoigt

\section{Bibliografi:}

David Donachie (f. 1944):

By the Mast Divided (2005)

An Awkward Commmission (2006)

A Shot Rolling Ship (2007) Flag of Truce (2008) The Admirals' Game (2008)

An Ill Wind (2009)

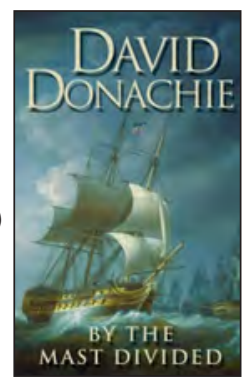

C.S. Forester (1899-1966):

The Happy Return (1937)

A Ship of the Line (1938)

Flying Colours (1938)

The Commodore (1945)

Lord Hornblower (1946)

Mr. Midshipman Hornblower (1950)

Lieutenant Hornblower (1952)

Hornblower and the Atropos (1953)

Hornblower in the West Indies (1958)

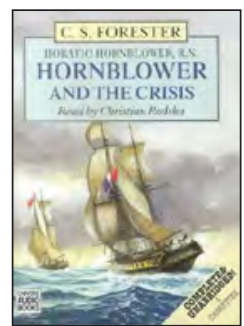

Hornblower and the Hotspur (1962)

Hornblower and the Crisis (1967) 
Seth Hunter:

The Time of Terror (2008)

The Tide of War (2009)

The Price of Glory (2010)

Alexander Kent (f. 1924):

To Glory We Steer (1968)

Form Line of Battle (1969)

Enemy In Sight! (1970)

Flag Captain (1971)

Sloop Of War (1972)

Command a King's Ship (1973)

Signal - Close Action! (1974)

Richard Bolitho, Midshipman (1975)

Passage To Mutiny (1976)

The Inshore Squadron (1977)

In Gallant Company (1977)

Midshipman Bolitho and the 'Avenger' (1978)

Stand Into Danger (1980)

A Tradition Of Victory (1981)

Success To The Brave (1983)

Colours Aloft! (1986)

Honour This Day (1987)

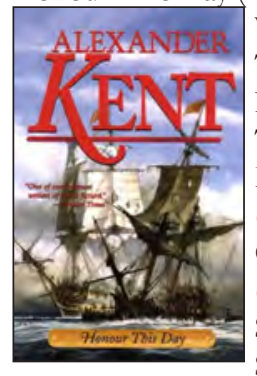

With All Despatch (1988)

The Only Victor (1990)

Beyond The Reef (1992)

The Darkening Sea (1993)

For My Country's Freedom (1995)

Cross Of St. George

(1996)

Sword of Honour (1998)

Second to None (1999)

Relentless Pursuit (2001)

Man of War (2003)

Band Of Brothers (2006)

Heart of Oak (2007)

Dewey Lambdin (f. 1945):

The King's Coat (1989)

The French Admiral (1990)

The King's Commission (1991)

The King's Privateer (1992)

The Gun Ketch (1993)

H.M.S. Cockerel (1995)

A King's Commander (1997)

Jester's Fortune (1999)
The King's Captain (2000)

Sea of Grey (2002)

Havoc's Sword (2003)

The Captain's Vengeance

$$
\text { (2004) }
$$

A King's Trade (2006)

Troubled Waters (2008)

The Baltic Gambit (2009)

King, Ship and Sword

(2010)

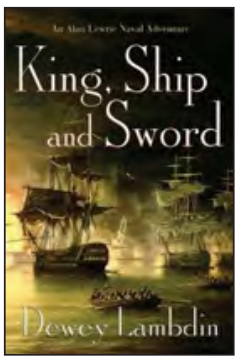

Dudley Pope (1925-1997):

Ramage (1965)

Ramage and the Drumbeat (1968)

Ramage and the Freebooters (1969)

Governor Ramage RN (1973)

Ramage's Prize (1974)

Ramage and the Guillotine (1975)

Ramage's Diamond (1976)

Ramage's Mutiny (1977)

Ramage and the Rebels (1978)

The Ramage Touch (1979)

Ramage's Signal (1980)

Ramage and the Renegades (1981)

Ramage's Devil (1982)

Ramage's Trial (1984)

Ramage's Challenge (1985)

Ramage at Trafalgar (1986)

Ramage and the Saracens (1988)

Ramage and the Dido (1989)

Peter Smalley:

HMS Expedient (2006)

Port Royal (2007)

Barbary Coast (2008)

The Hawk (2009)

The Gathering Storm (2010)

The Pursuit (2010)

Julian Stockwin (f. 1944):

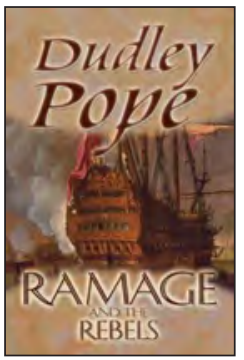

Kydd (2001)

Artemis (2002)

Seaflower (2003) 


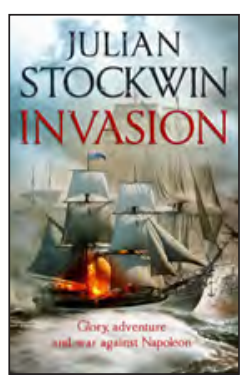

Mutiny (2003)

Quarterdeck (2005)

Tenacious (2005)

Command (2007)

The Admiral's Daughter (2007)

Treachery (2009)

Invasion (2009)

Victory (2010)

Richard Woodman (f. 1944):

An Eye of the Fleet (1981)

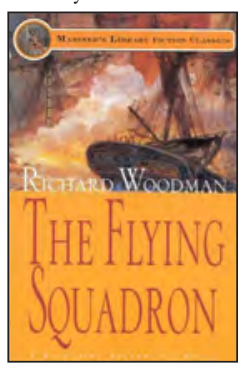

A King's Cutter (1981)

A Brig of War (1983)

The Bomb Vessel (1984)

The Corvette (1985)

1805 (1985)

Baltic Mission (1988)

In Distant Waters (1988)

A Private Revenge (1990)

Under False Colours (1991)

The Flying Squadron (1992)

Beneath the Aurora (1995)

The Shadow of the Eagle (1997)

Ebb Tide (1998)

\section{Danske oversættelser:}

\section{C.S. Forester:}

Kommandør Hornblower (1941)

Noter

1 Tak til Theis Lund, der har bekræftet denne oplysning.

2 Venligst meddelt mig af dr phil Karl-Erik Frandsen.
Kaptajn Hornblower (1942)

Hornblower i Østersøen (1947)

Lord Hornblower (1948)

Hr. kadet Hornblower (1951)

Løjtnant Hornblower (1953)

Hornblower på "Atropos" (1954)

Hornblower i Vestindien (1961)

Hornblower går i aktion (1963)

Alexander Kent:

De stolte skibe (1974)

I slagorden (1975)

Vejen til mytteri (1978)

Admiral Bolitho (1980)

Patrick O'Brian:

Kommandør (1998)

H.M.S. Surprise (2000)

Den første kommando (2000)

Togtet til Mauritius (2003)

Elendighedens ø (2004)

Dudley Pope:

Med flaget i top (1966)

Klart skib (1968)

Søløjtnant Ramage og fribytterne (1981)

Orkan og de franske kapere (1982)

Ramage og kaperkaptajnen (1983)

Ramage i guillotinens skygge (1984)

Kaptajn Ramage i Middelhavet (1985)

Ramage i slaget ved Trafalgar (1989)

3 Johanne Duus Hornemann, "Bøger i serier er vores fiktive familie". Kristeligt Dagblad 28. december 2009. 